\title{
Low Cost Pulse Oximeter in Outpatient Department to Detect Severity of Respiratory Infection: Retrospective Study
}

\author{
Sandeep $\mathrm{H}^{1}$, Vinod Uplaonkar ${ }^{2}$ \\ ${ }^{1}$ Professor and HOD, Department of Pediatrics, GIMS, Kalaburagi, Karnataka, ${ }^{2}$ Assistant Professor, Department of Pediatrics, KBNIMS, Kalaburagi, Karnataka.
}

\section{Abstract}

Background: On an average, children below 5 years of age suffer about 5 episodes of ARI per child per year, thus accounting for about 238 million attacks. ARI is responsible for about $30-50 \%$ of visits to hospital under 5-mortality rate, pneumonia consists $19 \%$ of deaths as compared to diarrhea (17\%), measles $(4 \%)$. This reduction in death rate in diarrhea is due to cheap and effective oral rehydration therapy diseases. Subjects and Methods: The study was conducted over period of one year from feb 2017 to feb 2018, overall hospitalized children with age group from 2months-60 months were included in the present study. Children who were with respiratory complaints like fever, cough, breathing difficulty were included. Results: In present study, all the children presenting with respiratory symptoms were analyzed and pulse oximeter were used when clinical findings were in conclusive for hospitalization. Conclusion: It was found that hypoxemia was common in patients with ALRI more show in infants then in children.

Keywords: Pulse Oximeter, Respiratory Infection, Hospitalized Children.

Corresponding Author: Dr Vinod Uplaonkar, Assistant Professor, Department of Pediatrics, KBNIMS, Kalaburagi, Karnataka.

Received: January 2019

Accepted: February 2019

\section{Introduction}

In developing nation like India outpatient department cater majority of illness particularly in our area which is considered to be backward region. Most among in pediatric outpatient department being diarrhea respiratory illness both (URI\&LRI), fever and malnutrition. Diarrhea cases with severe dehydration are always referred to inpatient department and less severe are advised oral rehydration solution whereas respiratory illness are usually treated with oral medications with introduction of low cost pulse oximeters, accurate measurement of saturation in younger patien $\mathrm{t}$ and direct assessment of hypoxemia helped many practitioners to identify early and refer to center where it can be treated better.

Acute lower respiratory infection (ALRI) are leading cause of mortality and morbidity among children, causing about $1 / 3$ rd of all deaths in childhood. ${ }^{[1]}$ Reliance on single clinical signs may not be optimal, as some clinical signs like lower chest in drawing or fast breathing may be sensitive but not very specific for identification of the hypoxemia. Whereas, other signs like cyanosis, unable to drink, grunting or lethargy, etc., may be very specific, but not very sensitive. ${ }^{[2]}$ No single clinical sign, or combination of signs, accurately predict hypoxemia in has been found to be a reliable predictor of hypoxemia. In all children. ${ }^{[3-6]}$ Oxygen saturation which is regarded as fifth vital sign 12,13 and measuring arterial oxygen saturation, often obviates the need for arterial blood samples. Pulse oximetry is non invasive and accurate method of measuring arterial oxygen saturation, is far the best method. ${ }^{[3-6]}$

On an average, children below 5 years of age suffer about 5 episodes of ARI per child per year, thus accounting for about 238 million attacks. ARI is responsible for about 30$50 \%$ of visits to hospital under 5-mortality rate, pneumonia consists $19 \%$ of deaths as compared to diarrhea $(17 \%)$, measles (4\%). This reduction in death rate in diarrhea is due to cheap and effective oral rehydration therapy diseases. In measles it is due to proper immunization. pulse oximeter usage decreases the hospitalization and mortality.

\section{Subjects and Methods}

The current study on low cost pulse oximeter was done at outpatient department of KBNIMS ; one year data analysed from the on duty pediatricians at outpatient department

The study was conducted over period of one year from feb 2017 to feb 2018 , overall hospitalized children with age group from 2months- 60 months were included in the present study. Children who were with respiratory complaints like fever, cough, breathing difficulty were included.

All the children were examined for clinical signs and pulse oximeter was applied for 30 seconds to 1 minutes and reading were recorded in outpatient form.

Brief history ,duration of illness ,fever ,breathlessness ,refusal to feeds or intolerance were recorded in the op form 
.critical patient with poor pulses, shock and central cyanosis were directly referred to in patient department and were excluded from present study

The child was examined and the following signs were recorded: appearance, weight, height, pulse rate, respiratory rate, (counted for 60 seconds when child is quiet and at rest) Cyanosis, chest in drawing, grunting, nasal flaring, pallor, air entry, abnormal breath sounds crepitation or rhonchi on auscultation.

\section{Results}

Total number of OPD patients analyzed with pulse oximeter were 2000,among them 850 patient s were admitted to in patient subsequently for monitoring and treatment.

Table 1: Age wise Distribution.

\begin{tabular}{|l|l|l|}
\hline Age Group & Number of Patients & Percentage \\
\hline $2-5$ months & 480 & 24.0 \\
\hline $6-11$ months & 428 & 21.4 \\
\hline $12-23$ months & 326 & 16.3 \\
\hline $24-35$ months & 378 & 18.9 \\
\hline $36-60$ months & 388 & 19.4 \\
\hline Total & 2000 & 100 \\
\hline
\end{tabular}

Above table displays increase in respiratory infections at younger age group with more Severity

Table 2: Age group of Patients enrolled for inpatient care.

\begin{tabular}{|l|l|l|}
\hline Age Group & $\begin{array}{l}\text { Number of } \\
\text { Patients }\end{array}$ & Percentage \\
\hline $2-5$ months & 300 & 37.5 \\
\hline $6-11$ months & 160 & 20.0 \\
\hline $12-23$ months & 140 & 17.5 \\
\hline $24-35$ months & 120 & 15.0 \\
\hline $36-60$ months & 080 & 10.0 \\
\hline Total & 800 & 100 \\
\hline
\end{tabular}

Table shows increase in the severity of illness in younger age group of 2 month -11 months compared to older age group.

Table 3: Mean SPO2 Values
\begin{tabular}{|l|l|}
\hline Age Group & SPO2 values \\
\hline $2-5$ months & $82.33-2.99^{*}$ \\
\hline $6-11$ months & $83.12-3.04^{*}$ \\
\hline $12-23$ months & $83.8-3.28$ \\
\hline $24-35$ months & $90.1-2.73$ \\
\hline $36-60$ months & $89.3-3.88$ \\
\hline
\end{tabular}

As a group, Infants 2-11mo of age had a significant lower mean spo 2 levels than the older children $\mathrm{p}<0.001$ by $\mathrm{t}-$ test

\section{Discussion}

Respiratory illness accounts for major turnover in outpatient department of any medical college hospital. Severity assessment of this respiratory illness at the level of outpatient with simple hand held device like pulse oximeter helps not only for hospitalization but also to analyze the level of severity and need for intensive ward care.

Hypoxemia is the most serious manifestation of severe respiratory illness in children and strong risk factors for mortality. The case fatality rate is inversely proportional to the oxygen saturation of arterial blood.

Pulse oximetry objectively measures the severity of disease, accurately determines whether oxygen is needed, and permits. Maximal benefit from pulse oximetry requires easy and cheap access to oxygen therapy. Pulse oximetry can reliably detect hypoxemia at all altitudes.

Therefore pulse oximetry should be considered a routine adjunct in clinical assessment of children presenting with respiratory illness. And can be included as fifth vital

Pulse oximetry was used to the know the need for in patient care in the following study. At what level of SpO2 should oxygen be supplemented to patients with ARI is of major concern.

In present study, all the children presenting with respiratory symptoms were analyzed and pulse oximeter were used when clinical findings were in conclusive for hospitalization .It was found that hypoxemia was common in patients with ALRI more show in infants then in children. Early recognition of hypoxemia and its prevalence is studied.

\section{Table 4: Comparative Study}

\begin{tabular}{|l|l|l|}
\hline Name of worker & $\begin{array}{l}\text { Observed high } \\
\text { incidence of LRTI } \\
\text { age group }\end{array}$ & Incidence \\
\hline Singhi et al.6 & $2-11$ months & $16.1 \%$ \\
\hline & $12-60$ months & $8.5 \%$ \\
\hline Present study & $2-12$ months & $85.45 \%$ \\
\hline & $12-60$ months & $52.54 \%$ \\
\hline
\end{tabular}

When our study compared with singhi et al similar results were obtained Prevalence of severity is similar, young age group having more severity when compared to older age So early hospitalization decreases the mortality in this age group.

\section{Conclusion}

Pulse oximetry should be considered a routine adjunct in clinical assessment of children presenting with respiratory illness. And can be included as fifth vital.

\section{References}

1. Garenne M, Ronsamans C, Campbell $\mathrm{H}$. The magnitude of mortality countries. World health statistics Quarterly 1992; 45: 180-191

2. American association for resp care AARC clinical practice Guideline; pulse oximetry. Respir care 1991; 361(12): 1406-1409.

3. Wang EE, Milner RA, Navas L- American review of respiratory disease-1992.

4. T dyke, N .Brown Hypoxia in Childhood Pneumonia: better detection 


\section{Sandeep \& Uplaankar; Sewerity of Respiratary Infection}

and more oxygen needed in developing countries. British medical journal 1994; 308; 119-120.

5. Rakesh Lodha, Prateek Singh Bhaduria, Anoop Verghu. can clinical signs predict hypoxemia in papua new guinea children with moderate and severe pneumonia .

6. Singhi, Deep A Kaur. Prevalence and predictions of hypoxemia in acute respiratory infections presenting to pediatric emergency department, PGIMER.

7. Rakesh Lodha, Prakash Singh Bhaduria, SK Kabra Can clinical symptoms and signs accurately predict Hypoxemia in children with Acute Lower respiratory tract infections?

Copyright: () the author(s), 2019. It is an open-access article distributed under the terms of the Creative Commons Attribution License (CC BY 4.0), which permits authors to retain ownership of the copyright for their content, and allow anyone to download, reuse, reprint, modify, distribute and/or copy the content as long as the original authors and source are cited.

How to cite this article: Sandeep H, Uplaonkar V. Low Cost Pulse Oximeter in Outpatient Department to Detect Severity of Respiratory Infection: Retrospective Study. Asian J. Clin. Pediatr. Neonatol.2019;7(1):27-29.

DOI: dx.doi.org/10.21276/ajcpn.2019.7.1.7 